\title{
SATISFAÇÃO DO CLIENTE DAS COMPANHIAS AÉREAS BRASILEIRAS
}

\author{
Maria Cecilia Coutinho de Arruda \\ Professora Adjunta do Departamento de \\ Mercadologia da EAESP/FGV. \\ E-mail: carruda@eaesp.fgvsp.br
}

Marcelo Leme de Arruda Mestrando em Estatística do IME-USP. E-mail: zepaulo@br.homeshopping.com.br

RESUMO: A orientação para o cliente não é filosofia recente em marketing. Todavia, alguns setores da economia ainda não se encontram totalmente sensíveis a essa tendência, especialmente no Brasil. Modernamente, a integração entre qualidade e marketing vem sendo concretizada em modelos de MSC - Mensuração da Satisfação do Cliente -, ainda não utilizados no Brasil. Este estudo objetiva analisar a percepção de passageiros de três companhias aéreas brasileiras a respeito de alguns atributos dos serviços oferecidos que pareceram fundamentais para a imagem da marca observada, visando a sua melhoria e à fidelidade dos passageiros.

ABSTRACT: The customer orientation is not a recent philosophy in marketing. However, some economic sectors are not sensitive to such trends yet, mainly in Brazil. Nowadays, the quality-marketing integration has become concrete in CSM - Customer Satisfaction Measurement - models, scarcely used in Brazil. The purpose of this survey is to analyse the perception of passengers flying through three Brazilian airlines about some attributes of the services offered by them, which seemed crucial for the observed image. It also aimed to enhance the corporate image and the passengers' loyalty.

PALAVRAS-CHAVE: satisfação do cliente, companhias aéreas, comportamento do consumidor, imagem corporativa, atributos de serviço.

KEY WORDS: customer satisfaction, airlines, consumer behavior, corporate image, attributes of service. 
Não é desconhecido o fato de que o segredo do marketing de serviços é a qualidade. O cliente avalia o serviço pelo desempenho daquele que oferece ou realiza tal serviço. A percepção do desempenho varia conforme os atributos do referido serviço, e dela dependem a competitividade, a confiança e o sucesso das estratégias de marketing.

Atualmente as empresas não apenas produzem, mas desempenham os serviços. A avaliação do cliente é o foco da vantagem competitiva. Quando o preço dos serviços é o mesmo, a qualidade do serviço se torna o fator determinante da escolha por parte do cliente. ${ }^{\prime}$

\section{OBJETIVO DO ARTIGO}

Procurou-se neste artigo analisar a percepção de passageiros de três companhias aéreas brasileiras a respeito de alguns atributos dos serviços oferecidos e que pareceram fundamentais para a imagem da marca observada.

\section{A AVALIAÇÃo dA QUALIDADE DOS SERVIÇOS}

Uma revisão da bibliografia sobre qualidade dos serviços permite notar que a maioria dos autores apóia-se fortemente nos trabalhos de Leonard L. Berry, A. Parasuraman e Valerie A. Zeithaml. Entendeu-se, assim, que uma síntese da obra básica dos dois primeiros autores forneceria o suporte teórico necessário para o desenvolvimento do presente artigo. ${ }^{2}$ Aspectos não abordados no referido livro-texto e de interesse para nossos objetivos constarão deste estudo e serão oportunamente indicados.

Enquanto no marketing de bens tangíveis as mercadorias são produzidas e estão disponíveis antes de serem vendidas, no marketing de serviços dá-se o contrário: estes são vendidos antes de serem produzidos. A intangibilidade faz com que a experiência seja um fator primordial no processo de compra, sendo esta obtida tanto com o marketing de pós-venda quanto com as comunicações boca a boca, que costumam substituir a experiência direta. ${ }^{3}$

Os executores dos serviços são responsáveis pela criação da consciência da marca, pela indução dos clientes à análise antes da venda e pela demonstração dos benefícios. Elaboram a preferência pela marca, com maior eficácia, depois da venda. Berry \& Parasuraman mencionam o exemplo dos produtores de serviços de uma companhia aérea, em que os funcionários interagem com os clientes ao emitir as passagens; os comissários de bordo, ao atendê-los durante o vôo; os carregadores de bagagem, imediatamente antes e após a viagem; e assim por diante. A maneira como cada um se comporta diante do cliente - como age, o que diz, o que deixa de dizer, sua aparência - pode influenciar a lealdade do cliente, levando-o a comprar outras vezes da empresa. ${ }^{4}$

\section{OS ATRIBUTOS DO SERVIÇO}

Destacam-se, no Quadro 1, os atributos cruciais apontados, em ordem de importância, pelo público de cinco empresas de serviços, numa pesquisa realizada junto a 1.900 clientes. $^{5}$

Quadro 1 - Principais atributos do serviço

\begin{tabular}{|l|l|}
\hline Confiabilidade & $\begin{array}{l}\text { Capacidade de prestar o } \\
\text { serviço prometido, de forma } \\
\text { confiável e com precisão. }\end{array}$ \\
\hline Tanglbilidade & $\begin{array}{l}\text { Aparência física de instalações, } \\
\text { equipamentos, pessoal e } \\
\text { materiais de comunicação. }\end{array}$ \\
\hline Sensıbilidade & $\begin{array}{l}\text { Disposição para ajudar o } \\
\text { cliente e proporcionar com } \\
\text { presteza um serviço. }\end{array}$ \\
\hline Segurança & $\begin{array}{l}\text { Conhecimento e cortesia de } \\
\text { empregados e sua habilidade } \\
\text { para transmitir confiança e } \\
\text { confiabilidade. }\end{array}$ \\
\hline $\begin{array}{l}\text { Empatia } \\
\text { Fonte: BERRY, Leonard L., PARASURAMAN, A. earinho } \\
\text { individualizados } \\
\text { proporcionados aos clientes. }\end{array}$ \\
qualidade. São Paulo: Maltese-Norma, 1992. p.30. \\
\hline
\end{tabular}

Um atributo essencial é a confiabilidade do serviço, ou seja, o desempenho confiável e preciso do serviço. Um cliente passa a não acreditar numa empresa quando o serviço lhe é prestado de maneira descuidada, com erros possíveis de ser evitados, com promessas não cumpridas. No caso de companhias aéreas, por exemplo, não basta que os pilotos sejam normalmente dignos de confian- 
ça. O risco é alto, tanto em termos de segurança como financeiramente.

O serviço que é bem feito logo na primeira vez atrai a confiabilidade dos clientes, ao mesmo tempo em que contribui significativamente para os lucros da empresa. Da mesma forma, o cumprimento fiel das promessas mantém essa confiabilidade, permitindo à empresa competir eficazmente, construir uma reputação em torno da marca, elevar os índices de retenção dos clientes atuais (evitando o custo de conseguir novos), fechar novos negócios e aumentar a comunicação boca a boca, promovendo assim a empresa. ${ }^{6}$

Oferecer um serviço sem erros, em tempo real, constitui o grande desafio de uma empresa. Isso implica que ela deve se tornar líder de mercado, testar e retestar inteiramente o serviço, e formar uma infra-estrutura organizacional para esse serviço sem erros. ${ }^{7}$ A inevitabilidade das falhas dos serviços, porém, deve também ser capitalizada, de forma que a recuperação excelente do serviço seja uma boa oportunidade para reforçar o relacionamento com os clientes e criar fidelidade de sua parte. ${ }^{8}$ Sem dúvida os clientes prestam mais atenção ao desempenho do prestador do serviço feito pela segunda vez do que se tudo houvesse funcionado bem da primeira vez. ${ }^{9}$

Uma vez que a empresa chega a compreender os critérios de avaliação dos clientes, ela pode estabelecer um plano de aprimoramento dos seus serviços, ainda que muitos vejam nisso grande dificuldade. ${ }^{10}$ Algumas empresas não admitem que possam apresentar problemas de qualidade de serviços porque muitos clientes insatisfeitos simplesmente não reclamam. Williams menciona que uma pesquisa recente junto a 100.000 passageiros assíduos de companhias aéreas nos Estados Unidos indicou que a alimentação ocupou a $14^{a}$ posição na lista de serviços oferecidos pelas empresas. Ainda que tradicionalmente os consumidores comentem duas vezes mais sua insatisfação do que sua satisfação em relação a um produto ou serviço, os passageiros não costumam reclamar da comida, mas guardam uma impressão negativa da empresa aérea. ${ }^{\text {" }}$

\section{A ADMINISTRAÇÃO DAS EXPECTATIVAS}

Os clientes avaliam a qualidade do serviço comparando o que desejam ou esperam com aquilo que obtêm. Importante se torna, portan- to, que a empresa saiba não só administrar as expectativas de seus clientes em relação aos serviços oferecidos, mas também superar tais expectativas. Existe uma diferença entre aquilo que os clientes acreditam que ocorrerá quando se deparam com o serviço (previsões) e aquilo que desejam que ocorra (desejos). ${ }^{12}$

Um estudo de Berry \& Parasuraman analisa os dois níveis de expectativa dos clientes: um desejado e outro adequado. O nível de serviço desejado é um misto do que o cliente acredita que pode ser com o que deveria ser. Existe uma zona de tolerância entre os dois níveis, constituindo o âmbito do desempenho do serviço que o cliente considera satisfatório. Um desempenho abaixo da zona de tolerância gera frustração no cliente e reduz sua lealdade. Acima da zona de tolerância, o desempenho causará uma surpresa agradável aos clientes, reforçando sua lealdade. ${ }^{13}$

Figura 1 - Níveis de expectativa

\begin{tabular}{|c|}
\hline Serviço desejado \\
Zona de tolerância \\
\hline Serviço adequado \\
\hline
\end{tabular}

A administração das expectativas do cliente será eficiente se forem mantidas as promessas de serviço feitas pela empresa, se o serviço for executado de forma confiável e se a comunicação com os clientes for eficaz. Assegurar que as promessas reflitam a realidade significa que qualquer promessa de serviço, explícita ou implícita, só será cumprida se estiver completamente dentro do controle da empresa. É preferível que o cliente reflita sobre o serviço real e não se prenda a características idealizadas ou glorificadas, que só o levarão à decepção, origem da desconfiança. ${ }^{14}$

\section{A ADMINISTRAÇÃo DAS EVIDÊNCIAS}

Uma forma de minimizar o descompasso entre a expectativa do cliente e sua satisfação com o serviço realizado é administrar as evidências, ou seja, os aspectos tangíveis associados ao serviço e que levam o cliente a compreendê-lo melhor. Os autores dividem estas evidências em três categorias: 0 ambiente físico, as comunicações e o preço. ${ }^{15}$

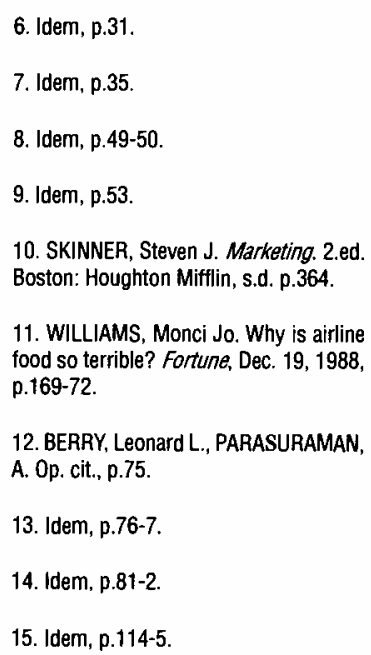

11. WILLIAMS, Monci Jo. Why is airline food so terrible? Fortune, Dec. 19, 1988, p.169-72.

12. BERRY, Leonard L., PARASURAMAN, A. Op. cit., p. 75 .

13. Idem, p.76-7.

14. Idem, p.81-2.

15. Idem, p.114-5. 
$\mathrm{O}$ ambiente físico abarca fatores ambientais (temperatura do ar, níveis de ruído), fatores de projeto (arquitetura, decoração, conforto) e fatores sociais (número, aparência $\mathrm{e}$ comportamento de clientes e empregados no ambiente de serviço). ${ }^{16}$

As comunicações são provenientes da própria empresa, de outros grupos interessados ou da mídia, que pode transmitir informações positivas ou negativas sobre o serviço. A empresa deve tentar trazer os tangíveis associados ao serviço para a linha de frente na estratégia das comunicações. Além disso, uma representação tangível do serviço pode ser criada para dar apoio à comunicação do significado e dos benefícios. Por fim, é possível tornar mais tangível a mensagem sobre o serviço, estimulando o bocaa-boca favorável, enfatizando a veracidade das promessas (garantia da execução dos serviços) e fazendo um uso criativo da evidência palpável na propaganda. ${ }^{17}$

As empresas têm geralmente especial preocupação com o preço, por ser este o único elemento do composto de marketing que gera rendimento. Todos os demais incorrem em custo. Dada a intangibilidade dos serviços, o preço se torna o único indicador visível do nível e da qualidade do serviço. Os preços demasiadamente baixos desvalorizam o serviço, pois o cliente questiona quanta especialização e/ou capacitação poderia estar sustentando tal serviço. Em contrapartida, os preços demasiado altos podem transmitir uma imagem de despreocupação da empresa em relação ao cliente, ou roubo. ${ }^{18}$

\section{O ENVOLVIMENTO DOS FUNCIONÁRIOS}

O papel das evidências é, portanto, essencial. Os empregados podem, por meio delas, entender e adquirir controle do serviço, formando sobre ele uma imagem men-

16. Idem, p.115-9.

17. Idem, p.119-22.

18. Idem, p.124.

19. Idem, p.125-6.

20. Idem, p.126.

21. Idem, p. $139-40$.

22. Idem, p.157.

23. Idem, p. 180 . tal. ${ }^{19} \mathrm{~A}$ estratégia de marketing subjacente a essa avaliação sugere, então:

- moldar as primeiras impressões;

- administrar a confiança;

- facilitar o serviço de qualidade;

- mudar a imagem (rompimento com atitudes existentes);

- proporcionar estímulo sensorial;

- socializar os empregados. ${ }^{20}$

A marca que a empresa apresenta não é necessariamente a que o cliente percebe. $O$ significado da marca é a impressão espontânea que o cliente tem e a classificação que ele faz da empresa. O significado da marca existe em função da sua apresentação, do conceito, qualidade e valor do serviço. ${ }^{21}$

\section{A MANEIRA COMO CADA UM SE COMPORTA DIANTE DO CLIENTE - COMO AGE, O QUE DIZ, O QUE DEIXA DE DIZER, SUA APARÊNCIA - PODE INFLUENCIAR A LEALDADE DO CLIENTE.}

As empresas de serviço podem aumentar sua participação de mercado atraindo novos clientes, aumentando o volume de negócios com os atuais e reduzindo os atritos com os clientes. ${ }^{22}$ Por outro lado, a empresa melhora sua capacidade de satisfazer as necessidades dos clientes externos se antes souber satisfazer as necessidades dos clientes internos. Para isso, é importante para a empresa: ${ }^{23}$

- concorrer pelo talento: contratar os melhores profissionais para realizar os serviços;

- oferecer uma idéia;

- preparar os funcionários para as suas incumbências;

- dar ênfase ao trabalho de equipe;

- influenciar o fator "liberdade";

- avaliar e recompensar;

- conhecer seus clientes.

\section{CONSIDERAÇÕES NO FINAL DA DÉCADA DE 90}

A abordagem de empresa ampliada, fundamental para o marketing de serviços na década de 90 , pressupôs a busca de parceiros com valores e necessidades empresariais comuns, pensando grande mas agindo pequeno, tendo como aliados os computadores, expandindo os conhecimentos, enxugando os serviços, com a eliminação ou automatização de atividades antes realizadas manualmente, e personalizando o serviço, com o uso da tecnologia. Isto posto, o processo de aperfeiçoamento da qualidade dos serviços 
não pode mais ser interrompido. Para evitar que isso aconteça, a empresa pode e/ou deve criar um sistema de informações sobre a qualidade do serviço, divulgar as estatísticas mais importantes sobre ela, avaliar a influência da má qualidade nos lucros, dar ênfase à qualidade individual e tornar-se modelo de liderança no serviço. ${ }^{24}$

\section{Metodologla da pesquisa}

A partir de um modelo para mensuração da satisfação do consumidor sugerido por Naumann \& Giel, foi elaborado o questionário aplicado aos passageiros de vôos nacionais e internacionais. ${ }^{25}$ Após um pré-teste com 11 questionários (realizado no Aeroporto Internacional de Cumbica, em Guarulhos) e sucessivas incorporações de sugestões, chegou-se à versão final do questionário.

A coleta de dados no Brasil correspondeu à aplicação de 600 questionários aos passageiros nas salas de embarque de vôos aéreos nacionais e internacionais de três companhias aéreas brasileiras: Transbrasil, Varig e VASP. A amostra de consumidores a serem entrevistados foi composta de passagei- ros dos aeroportos internacionais de São Paulo (Cumbica), Rio de Janeiro (Galeão), Belo Horizonte (Tancredo Neves) e Porto Alegre (Salgado Filho), por serem esses os centros urbanos responsáveis pelo maior tráfego aéreo no Brasil.

Pelo projeto de pesquisa, seriam respondidos 600 questionários, sendo 300 para vôos nacionais e 300 para vôos internacionais. Os 300 questionários para vôos nacionais seriam divididos em 75 para cada cidade; esses 75 questionários, por sua vez, corresponderiam a 25 para cada companhia aérea. Da mesma forma seriam divididos os 300 questionários para vôos internacionais. As companhias aéreas a serem pesquisadas seriam as mesmas: Transbrasil, Varig e VASP. Os questionários seriam preenchidos por um passageiro a cada grupo de dez que fossem contados por um dos entrevistadores, assegurando a sistematização da coleta de dados.

No projeto de pesquisa, também foi previsto que as entrevistas seriam realizadas em cada cidade durante três dias consecutivos, sendo dois dias úteis e um de fim de semana, das 8 às 18 horas para vôos nacionais e das $13 \mathrm{~h} 30$ às $23 \mathrm{~h} 30$ para vôos internacionais. Um

Tabela 1 - Distrlbuição dos questionários por cidade e por ala

\begin{tabular}{|lccc|}
\hline $\begin{array}{c}\text { Cidades de } \\
\text { embarque }\end{array}$ & $\begin{array}{c}\text { Vôos } \\
\text { nacionais }\end{array}$ & $\begin{array}{c}\text { Vóos } \\
\text { Internacionals }\end{array}$ & Total \\
\hline \hline Belo Horlzonte & 80 & 15 & 95 \\
\hline Rlo de Janeiro & 81 & 23 & 104 \\
\hline Porto Alegre & 76 & 52 & 128 \\
\hline Săo Paulo & 63 & 210 & 273 \\
\hline Total & 300 & 300 & 600 \\
\hline
\end{tabular}

Tabela 2 - Companhlas menclonadas como últimas

\begin{tabular}{|lcllll|}
\hline \multicolumn{1}{|c}{ Companhia } & Ne & \multicolumn{1}{c}{ Companhla } & No & Companhla & Ne \\
\hline \hline Varig & 108 & Alr France & 3 & Viasa & 2 \\
\hline VASP & 78 & Iberla & 3 & Aéreo Mexicana & 1 \\
\hline TAM & 52 & Aerocancún & 2 & Aeroperú & 1 \\
\hline Transbrasil & 36 & Altalla & 2 & Alr Vlas & 1 \\
\hline Aerolíneas Argentinas & 23 & Delta & 2 & Avianca & 1 \\
\hline Amerlcan Alrines & 19 & JAL & 2 & British Airways & 1 \\
\hline Rlo-Sul & 9 & Lloyd Bollviano (LAB) & 2 & Canadlan Alrlines & 1 \\
\hline United Alrlines & 9 & Nordeste & 2 & Continental Alrlines & 1 \\
\hline KLM & 4 & Pantanal & 2 & Fly & 1 \\
\hline Lufthansa & 4 & Paraguayas (LAP) & 2 & Swiss Air & 1 \\
\hline TAP & 4 & Pluna & 2 & Tower Air & 1 \\
\hline
\end{tabular}

24. Idem, p.221

25. NAUMANN, Earl, GIEL, Kathleen. Customer satistaction measurement and management. Cincinatti: Thompson Executive Press, 1995. p.433-42. 
entrevistador, com função de contador, entregaria um questionário impresso em papel de cor forte (para ser facilmente localizado à distância) àquele passageiro sistematicamente selecionado. Os outros dois entrevistadores explicariam a estes passageiros o que fosse necessário e recolheriam no final os questionários respondidos.

$\mathrm{Na}$ realidade, não foi possível respeitar as cotas de cada cidade, como previsto. A inexistência de vôos internacionais da VASP em Belo Horizonte e Porto Alegre ocasionou a necessidade de a cota ser compensada em outras cidades. Além disso, a maioria dos passageiros utilizava apenas o trecho nacional dos vôos internacionais (que de fato partiriam de São Paulo). Por essa razão, não foi possível também manter a regra de entrevistar um a cada dez passageiros, já que a quantidade de consumido-

Tabela 3 - Resultados descritivos

\begin{tabular}{|c|c|c|c|c|c|c|}
\hline \multirow{2}{*}{$\begin{array}{l}\text { Grupo de companhias } \\
\text { Atributos }\end{array}$} & \multicolumn{2}{|c|}{$\begin{array}{l}\text { Brasileiras últimas } \\
\text { (290 respostas) }\end{array}$} & \multicolumn{2}{|c|}{$\begin{array}{l}\text { Estrangeiras últimas } \\
\text { (94 respostas) }\end{array}$} & \multicolumn{2}{|c|}{$\begin{array}{c}\text { Brasileiras atuais } \\
\text { (598 respostas) }\end{array}$} \\
\hline & Médla & DP & Média & DP & Média & DP \\
\hline Perda de bagagens & 4,06 & 1,08 & 3,63 & 1,22 & 4,08 & 0,98 \\
\hline Limpeza dos toaletes & 3,97 & 0,83 & 3,57 & 1,05 & 3,95 & 0,86 \\
\hline Segurança & 3,97 & 0,79 & 4,08 & 0,69 & 4,12 & 0,69 \\
\hline Bagagem daniflcada & 3,95 & 0,96 & 3,63 & 1,21 & 4,08 & 0,89 \\
\hline Serviço de bordo & 3,95 & 0,82 & 3,60 & 0,88 & 4,02 & 0,80 \\
\hline Atendimento no check-in & 3,93 & 0,86 & 3,75 & 0,86 & 3,98 & 0,84 \\
\hline $\begin{array}{l}\text { Serviço de confirmaçāo } \\
\text { dos vôos }\end{array}$ & 3,93 & 0,82 & 3,74 & 0,90 & 3,88 & 0,92 \\
\hline Serviço de terra & 3,93 & 0,79 & 3,73 & 0,79 & 3,97 & 0,78 \\
\hline Cortesia & 3,88 & 0,92 & 3,67 & 1,00 & 3,92 & 0,93 \\
\hline Credibilidade & 3,86 & 0,92 & 3,77 & 0,90 & 3,92 & 0,80 \\
\hline $\begin{array}{l}\text { Rapidez no serviço de } \\
\text { reservas }\end{array}$ & 3,86 & 0,89 & 3,81 & 0,82 & 3,89 & 0,89 \\
\hline $\begin{array}{l}\text { Temperatura/umidade no } \\
\text { interior da aeronave }\end{array}$ & 3,85 & 0,73 & 3,71 & 0,84 & 3,87 & 0,75 \\
\hline $\begin{array}{l}\text { Resposta com precisão } \\
\text { as dúvidas }\end{array}$ & 3,79 & 0,86 & 3,70 & 0,88 & 3,76 & 0,91 \\
\hline Pronta resposta às dúvidas & 3,77 & 0,89 & 3,65 & 0,85 & 3,83 & 0,89 \\
\hline Cobertas e travesseiros & 3,75 & 0,96 & 3,75 & 1,05 & 3,81 & 0,94 \\
\hline $\begin{array}{l}\text { Assistência para as } \\
\text { conexóes }\end{array}$ & 3,73 & 0,93 & 3,70 & 1,05 & 3,76 & 0,93 \\
\hline $\begin{array}{l}\text { Compreensão das } \\
\text { necessidades }\end{array}$ & 3,72 & 0,90 & 3,71 & 0,95 & 3,76 & 0,87 \\
\hline $\begin{array}{l}\text { Assistêncla a pedidos } \\
\text { especiais }\end{array}$ & 3,69 & 1,01 & 3,46 & 1,04 & 3,65 & 1,02 \\
\hline Conforto & 3,68 & 0,97 & 3,49 & 1,04 & 3,75 & 0,90 \\
\hline Pontualidade na chegada & 3,65 & 1,08 & 3,73 & 1,05 & 3,73 & 0,99 \\
\hline Preço & 3,58 & 0,73 & 3,20 & 0,66 & 3,37 & 0,70 \\
\hline Pontualidade na saída & 3,58 & 1,16 & 3,64 & 1,15 & 3,53 & 1,12 \\
\hline $\begin{array}{l}\text { Rapidez na liberação da } \\
\text { bagagem }\end{array}$ & 3,53 & 1,00 & 3,50 & 0,95 & 3,63 & 0,97 \\
\hline Alimentação & 3,36 & 1,13 & 3,33 & 1,09 & 3,48 & 1,01 \\
\hline Qualidade de serviço & 3,66 & 0,79 & 3,70 & 0,74 & 3,79 & 0,78 \\
\hline Recomendação & 2,35 & 0,66 & 2,34 & 0,72 & 2,47 & 0,61 \\
\hline
\end{tabular}


res que preenchiam as condições para responder ao questionário não era suficiente para a adoção desse critério.

Os questionários respondidos ficaram distribuídos conforme indicado na Tabela 1 .

Os passageiros foram abordados após o check-in, enquanto aguardavam a chamada na sala de embarque dos vôos nacionais e/ou internacionais das mencionadas companhias aéreas. Esses momentos se revelaram ideais, pois os passageiros tinham pouca distração e se encontravam no clima de viagem, portanto, sensíveis aos itens constantes do questionário.

Os horários não foram uniformes conforme previsto no projeto, uma vez que os vôos não se distribuíam regularmente ao longo das semanas.

Para que a coleta de dados não ficasse restrita àquelas três companhias em cujos vôos os passageiros estavam embarcando (aqui chamadas de atuais), o questionário foi elaborado de forma que os passageiros pudessem responder também sobre a última companhia (diferente da atual) pela qual tivessem realizado algum vôo nos 18 meses anteriores à pesquisa (aqui chamada de última). A Tabela 2 relaciona a distribuição das companhias mencionadas como últimas nos questionários.

\section{Análise dos dados}

De um modo geral, as questões respondidas foram analisadas segundo uma escala de cinco pontos ( 1 a 5 ) em que o valor 1 (muito ruim) expressa a reprovação extrema, enquanto o valor 5 (muito bom) significa a máxima aprovação do atributo pelo passageiro. Fugiram a essa escala as variáveis preço e recomendação. A variável preço assumiu valores de 1 (muito baixo) a 5 (muito alto) e, para a variável recomendação, os valores variaram entre 1 (não recomendaria) e 3 (recomendaria totalmente).

Os questionários preenchidos foram analisados, e as questões, submetidas a uma análise descritiva. A Tabela 3 apresenta médias e desvios-padrão das variáveis estudadas,

Tabela 4 - Correlações entre os atributos e a variável recomendaçăo

\begin{tabular}{|lll|}
\hline Atributo & Últimas & Atuals \\
\hline \hline Credıbllidade & 0,565 & 0,512 \\
\hline Resposta com preclsão às dúvidas & 0,463 & 0,451 \\
\hline Compreensão das necessidades & 0,448 & 0,444 \\
\hline Assistência a pedidos especiais & 0,445 & 0,437 \\
\hline Pronta resposta às dúvidas & 0,454 & 0,429 \\
\hline Cortesia & 0,459 & 0,416 \\
\hline Serviço de terra & 0,319 & 0,395 \\
\hline Alimentłção & 0,404 & 0,375 \\
\hline Rapidez na llberação da bagagem & 0,329 & 0,370 \\
\hline Conforto & 0,408 & 0,366 \\
\hline Atendlmento no check-ln & 0,365 & 0,359 \\
\hline Serviço de confirmação dos vôos & 0,343 & 0,352 \\
\hline Rapldez no serviço de reservas & 0,336 & 0,338 \\
\hline Pontualidade na saída & 0,454 & 0,324 \\
\hline Segurança & 0,273 & 0,324 \\
\hline Perda de bagagens & 0,263 & 0,309 \\
\hline Serviço de bordo & 0,384 & 0,306 \\
\hline Assistência para as conexões & 0,302 & 0,304 \\
\hline Temperatura/umidade no Interior da aeronave & 0,225 & 0,301 \\
\hline Pontualidade na chegada & 0,413 & 0,293 \\
\hline Cobertas e travesseiros & 0,261 & 0,264 \\
\hline Llmpeza dos toaletes & 0,307 & 0,245 \\
\hline Bagagem danificada & 0,193 & 0,231 \\
\hline Preço total & 0,098 & 0,123 \\
\hline & & \\
\hline
\end{tabular}


estratificadas pelos grupos de interesse, ou seja, as companhias aéreas: estrangeiras últimas, brasileiras últimas e brasileiras atuais.

O desempenho dos negócios foi analisado com base na disposição dos passageiros em recomendar a companhia aérea a outras pessoas. A satisfação dos passageiros, de um modo geral, influencia o desejo de recomendação e a lealdade desses passageiros em relação a futuras viagens. Isto foi determinado de acordo com o grau de satisfação das expectativas dos passageiros.

Para cada um dos 24 atributos foi calculada a correlação com a variável recomendação, com o intuito de identificar a importância dada pelos passageiros aos atributos na recomendação. A Tabela 4 apresenta essas correlações, estratificadas de acordo com os grupos de companhias atuais e últimas.

Como se pode ver na Tabela 4 , quase todos os atributos apresentaram pouca alteração quanto à sua importância na recomendação da última companhia em relação à atual. $\mathrm{O}$ atributo pontualidade na chegada foi $\mathrm{O}$ único a apresentar variação sensível (de 0,413 para 0,293 ), o que significa uma diminuição de sua importância na recomendação das companhias aéreas.

Para cada um dos 24 atributos foi calculada a correlação com a variável denominada qualidade de serviço, com a finalidade de identificar a importância conferida pelos passageiros aos atributos na formulação do conceito de qualidade de serviço. A Tabela 5 apresenta essas correlações, agrupadas de acordo com os estratos de companhias atuais e últimas.

As medidas de qualidade captam a primeira percepção dos produtos e serviços oferecidos. Compreendendo-se as correlações apresentadas na Tabela 5 como medidas de importância, pode-se ver, por exemplo, que credibilidade e compreensão das necessidades são os atributos mais levados em consideração pelos passageiros na percepção da qualidade de serviço.

As diferenças encontradas entre as companhias da última viagem e da atual podem constituir um indicador de qualidade

Tabela 5 - Correlaçōes entre os atributos e a varíavel qualidade

\begin{tabular}{|c|c|c|}
\hline Atrlbuto & Úitımas & Atuals \\
\hline Credibllidade & 0,642 & 0,648 \\
\hline Compreensāo das necessidades & 0,647 & 0,637 \\
\hline Pronta resposta d̀s dúvldas & 0,642 & 0,622 \\
\hline Resposta com precisăo d̀s dúvidas & 0,612 & 0,614 \\
\hline Cortesia & 0,591 & 0,566 \\
\hline Servlço de confirmaçáo dos vôos & 0,458 & 0,562 \\
\hline Rapldez no serviço de reservas & 0,516 & 0,552 \\
\hline Assistêncla a pedidos especials & 0,648 & 0,535 \\
\hline Serviço de terra & 0,498 & 0,519 \\
\hline Rapldez na llberação da bagagem & 0,556 & 0,511 \\
\hline Asslstência para as conexōes & 0,515 & 0,509 \\
\hline Conforto & 0,557 & 0,503 \\
\hline Allmentação & 0,513 & 0,502 \\
\hline Servlço de bordo & $\mathbf{0 , 5 3 1}$ & 0,485 \\
\hline Pontualldade na saída & 0,526 & 0,475 \\
\hline Atendlmento no check-in & 0,500 & 0,470 \\
\hline Segurança & 0,447 & 0,448 \\
\hline Temperatura/umldade no interlor da aeronave & $\mathbf{0 , 3 5 1}$ & 0,448 \\
\hline Pontualldade na chegada & 0,496 & 0,433 \\
\hline Cobertas e travesselros & 0,402 & 0,428 \\
\hline Limpeza dos toaletes & 0,396 & 0,427 \\
\hline Perda de bagagens & 0,396 & 0,406 \\
\hline Bagagem danificada & 0,291 & 0,317 \\
\hline Preço total & 0,105 & 0,018 \\
\hline
\end{tabular}


Tabela 6 - Diferenças encontradas entre os grupos de interesse

\begin{tabular}{|c|c|c|c|}
\hline Atrlbuto & Dlferenças detectadas & Médias em cada estrato & Nível descritivo \\
\hline \multirow[t]{3}{*}{ Preço } & brasilelras últimas & 3,58 & 0,0000 \\
\hline & brasilelras atuais & 3,37 & \\
\hline & estrangelras últimas & 3,20 & \\
\hline \multirow[t]{3}{*}{ Serviço de bordo } & estrangeiras últimas & 3,60 & 0,0001 \\
\hline & braslleiras últimas & 3,95 & \\
\hline & brasileiras atuals & 4,02 & \\
\hline \multirow[t]{3}{*}{ Limpeza de toaletes } & estrangeiras últimas & 3,57 & 0,0007 \\
\hline & brasileiras atuals & 3,95 & \\
\hline & brasileiras últimas & 3,97 & \\
\hline \multirow{3}{*}{$\begin{array}{l}\text { Bagagens } \\
\text { danlficadas }\end{array}$} & estrangeiras últimas & 3,63 & 0,0018 \\
\hline & brasileiras últimas & 3,95 & \\
\hline & braslleiras atuais & 4,08 & \\
\hline \multirow[t]{3}{*}{ Perda de bagagens } & estrangelras últimas & 3,63 & 0,0038 \\
\hline & brasileiras últimas & 4,06 & \\
\hline & brasileiras atuals & 4,08 & \\
\hline
\end{tabular}

que pode influenciar ou definir a escolha da próxima compra de passagem aérea. Os três grupos de interesse foram comparados com relação às médias de cada um dos 24 atributos a fim de identificar os pontos em que cada grupo se distingue dos demais. A Tabela 6 apresenta os resultados apenas das comparações em que foram detectadas diferenças significativas no nível de 0,01 .

Observando-se a Tabela 6, verificam-se três comportamentos diferentes. Os atributos denominados serviço de bordo, bagagens danificadas e perda de bagagens apresentaram-se melhores nas companhias brasileiras atuais do que nas brasileiras últimas, que, por sua vez, superaram as estrangeiras últimas. Do ponto de vista dos passageiros poder-se-ia imaginar que, nestes aspectos, as empresas brasileiras estão à frente das estrangeiras.

$\mathrm{O}$ atributo limpeza de toaletes apresentou piora das companhias brasileiras últimas em relação às atuais, embora ainda sejam superiores às companhias estrangeiras últimas.

Por fim, $o$ atributo preço apresentou uma redução das companhias brasileiras últimas em relação às atuais, ainda que as companhias estrangeiras últimas permaneçam com tarifas menores.

\section{Comentários finais}

Os passageiros que afirmaram ser alto o preço da passagem poderiam estar admitin- do indiretamente que tomaram uma decisão infeliz quando realizaram a compra. Por outro lado, os passageiros poderiam relutar em dizer que o preço da passagem foi baixo, por temer que as companhias utilizem essa informação para elevá-lo.

Alguns atributos foram apontados pelos passageiros com maior freqüência: perda de bagagens, segurança, bagagem danificada e serviço de bordo. Em contrapartida, algumas atividades poderiam ser consideradas críticas, pela distância entre expectativa e satisfação dos passageiros: alimentação, rapidez na liberação de bagagens, conforto e assistência a pedidos especiais. Estas quatro atividades, bem como os processos que a elas conduzem, deveriam constituir prioritariamente o foco dos esforços de melhoria nas companhias aéreas.

Os consumidores podem não ter elementos suficientes para avaliar, com precisão, os atributos dos produtos e serviços de uma companhia aérea. Valem-se, então, da imagem corporativa e a transferem ao produto ou serviço específico dessa empresa. Quanto mais real o valor da imagem corporativa, mais ele pode indicar ao consumidor o que esperar da companhia aérea. Enquanto a imagem positiva cria expectativas positivas, a imagem corporativa negativa pode sugerir ao passageiro incerteza e risco. 